\title{
Fatigue Performance of Injection-Molded Short E-Glass Fiber Reinforced Polyamide-6,6. II. Effects of Melt Temperature and Hold Pressure
}

\author{
Yuanxin Zhou, P. K. Mallick \\ Center for Lightweighting Automotive Materials and Processing, University of Michigan-Dearborn, \\ Dearborn, Michigan 48128
}

\begin{abstract}
Tensile and fatigue properties of an injection molded short E-glass fiber reinforced polyamide-6,6 have been studied as a function of two key injection molding parameters, namely melt temperature and hold pressure. It was observed that tensile and fatigue strengths of specimens normal to the flow direction were lower than that in the flow direction, indicating inherent anisotropy caused by injection molding. Tensile and fatigue strengths of specimens with weld line were significantly lower than that without weld lines. For specimens in the flow direction, normal to the flow direction and with weld line, tensile strength and fatigue strength increased with increasing melt temperature as well as increasing hold pressure. The effect of specimen orientation on the tensile and fatigue strengths is explained in terms of the difference in fiber orientation and skin-core morphology of the specimens. POLYM. COMPOS., 32:268-276, 2011. () 2010 Society of Plastics Engineers
\end{abstract}

\section{INTRODUCTION}

Injection molding is the most common manufacturing process for making plastic products, both large and small, for many different applications. Injection molding process parameters, such as melt temperature, mold temperature, and injection pressure, are known to affect not only the physical appearance and internal microstructure of an injection molded product, but also its performance due to their effects on the mechanical properties of the material [1]. For this reason, a number of investigators have considered and reported the effects of several key injection molding process parameters on the tensile and impact properties of both unfilled and short fiber reinforced polymers [2-11]. However, there are not many studies in the literature on the effects of injection molding parameters

Correspondence to: P.K. Mallick; e-mail: pkm@umich.edu Contract grant sponsor: TRW Education Foundation.

DOI 10.1002/pc.21045

Published online in Wiley OnlineLibrary (wileyonlinelibrary.com). (C) 2010 Society of Plastics Engineers on the fatigue properties of injection molded polymers. In an earlier article [12], we have reported the effects of melt temperature and hold pressure on the stress-controlled fatigue properties of talc-filled polypropylene. In this article, we will consider the effects of the same two process parameters on the stress-controlled fatigue properties of an injection molded short E-glass fiber-reinforced polyamide-6,6. Their effects on the weld line fatigue strength have also been examined in this article.

Short E-glass fiber reinforced polyamide-6,6 (GF/PA$6,6)$ has been selected as the material of interest in this study, since it is considered an important engineering polymer for many load-bearing commercial as well as industrial products where relatively high stiffness, creep resistance, and toughness are desired. It is also used in applications in which the product may experience longterm cyclic loading and therefore, is prone to fatigue failure. Many such applications are now found in automobiles, home appliances, office machines, and a variety of industrial and commercial products.

Mechanical behavior of short glass fiber reinforced polyamide-6,6 (GF/PA-6,6) has been the subject of many previous studies. For example, Thomason [13] has studied the influence of fiber strength and diameter on the mechanical properties of GF/PA-6,6. Akay et al. [14, 15] have reported the fracture toughness and impact behavior of GF/PA-6,6. Lévay et al. [16] have investigated the effect of testing conditions on the fracture characteristics of GF/PA 6,6. Jia and Kagan [17] conducted tension-tension fatigue tests on GF/PA-6,6 at $-40,23$, and $121^{\circ} \mathrm{C}$ and observed a significant decrease in the fatigue properties with increasing temperature. However, aging the fatigue specimens at $121^{\circ} \mathrm{C}$ for up to $1,000 \mathrm{hr}$ prior to fatigue testing did not cause any significant changes in the fatigue properties. Zhou and Mallick [18] examined the effects of specimen orientation, hole stress concentration, weld line and cycling frequency on the tension-tension fatigue properties of a GF/PA-6,6. Bernasconi et al. [19] reported the effect of fiber orientation on the fatigue behavior of a short glass fiber reinforced polyamide- 6 . In 
their experiments, fatigue specimens were cut out of injection molded plates at $0,30,60$, and $90^{\circ}$ angles with respect to the longitudinal axis of the plates. The fatigue strength was found to depend on the specimen orientation, with the highest value obtained at $0^{\circ}$ and the lowest value obtained at $90^{\circ}$. There are also several studies in which fatigue crack propagation rate in GF/PA-6,6 has been determined using fracture mechanics approach [20-22]. In one of these studies [22], fiber orientation was observed to have a significant influence on the fatigue resistance of $\mathrm{GF} / \mathrm{PA}-6,6$. The fatigue crack propagation rate was $\sim 15$ times faster when the fibers were parallel to the crack growth direction compared to when they were normal to the crack growth direction.

\section{EXPERIMENTAL}

The material investigated in this study was an injection molded short E-glass fiber reinforced polyamide-6,6 (GF/ PA-6,6), commercially available under the trade name Zytel-70G33HS1L (DuPont). The glass fiber content was $33 \%$ by weight, which was equivalent to $18 \%$ by volume. The number average fiber length of such a material was reported to be in the range of $0.4 \mathrm{~mm}$ [13]. The melting point of the polyamide- 6,6 resin is $260^{\circ} \mathrm{C}$. Square plates, $150 \mathrm{~mm} \times 150 \mathrm{~mm}$, were injection molded from dried pellets of GF/PA-6,6 in a single edge-gated mold with a central 25-mm diameter core (Fig. 1). The plate thickness was $2.5 \mathrm{~mm}$. A 90-ton Toyo injection molding machine was used to mold these plates. Three different melt temperatures were considered, namely $280^{\circ} \mathrm{C}, 310^{\circ} \mathrm{C}$, and $332^{\circ} \mathrm{C}$. The peak injection pressure was $103 \mathrm{MPa}$ for all plates, but the hold pressure was varied at three levels, namely 27.6 MPa, 55.2 $\mathrm{MPa}$, and 82.8 $\mathrm{MPa}$. The mold temperature was maintained at $35^{\circ} \mathrm{C}$. The following two groups of plates were injection molded:

(1) Group I: Hold pressure $=27.6 \mathrm{MPa}$ and Melt temperature $=280,310$, and $332^{\circ} \mathrm{C}$.

(2) Group II: Melt temperature $=310^{\circ} \mathrm{C}$ and Hold pressure $=27.6,55.2$, and $82.8 \mathrm{MPa}$.

Dog-bone shaped specimens were prepared from the injection molded plates in three different directions: parallel to the flow direction (L-direction specimens), normal to the flow direction (W-direction specimens), and with weld line (WL specimens). The specimen dimensions were $100 \mathrm{~mm}$ in overall length, $40 \mathrm{~mm}$ in gage length, and $12.7 \mathrm{~mm}$ in gage width. The locations of these specimens on the molded plates are shown in Fig. 1. For the WL specimens, the weld line was located at the midlength, normal to the specimen axis. The weld line was formed in the injection-molded plates as the flow front was divided by the 25.4-mm diameter core located at the center of the mold cavity and then joined behind the core.

Uniaxial tension tests and fatigue tests were performed on an MTS servohydraulic test machine. To prepare the

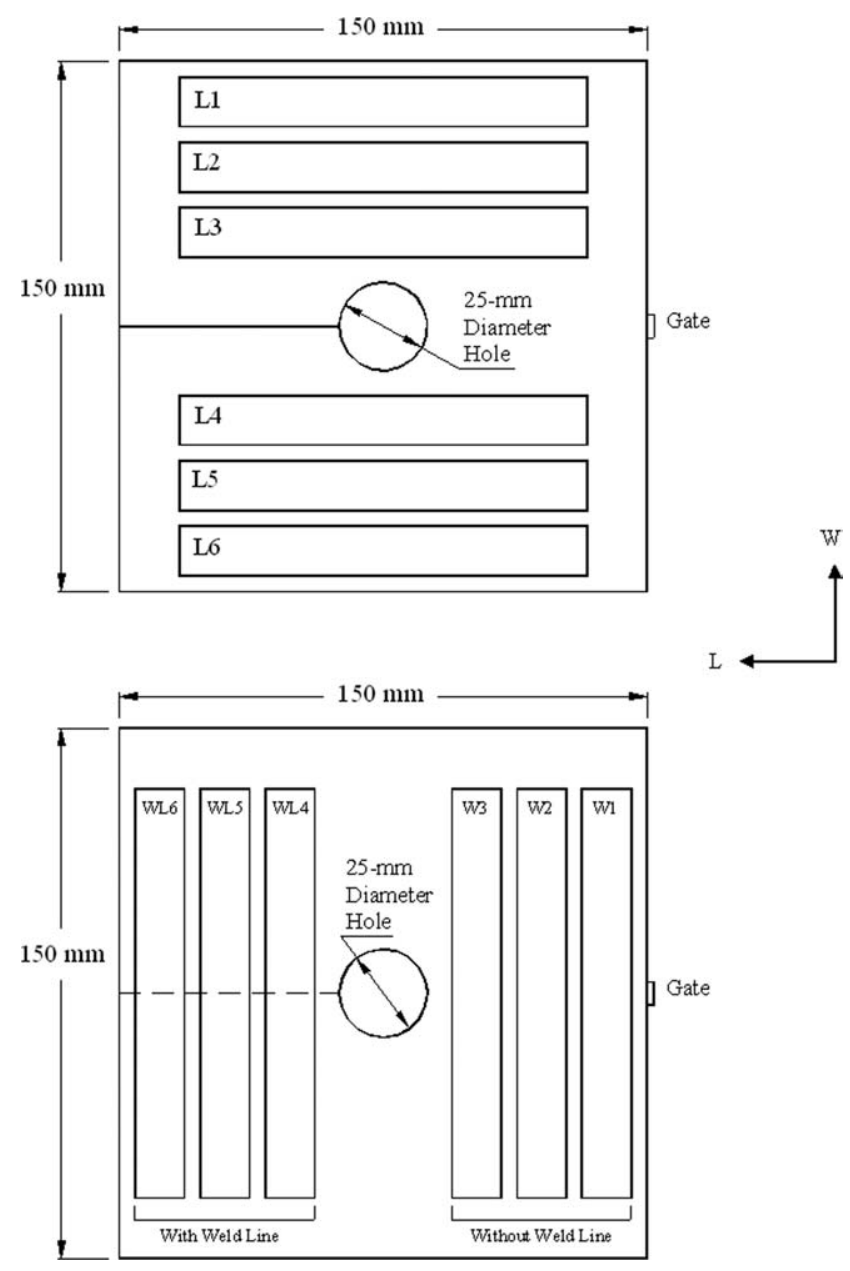

FIG. 1. Schematic of the injection molded plates showing the locations of L-direction (parallel to flow), W-direction (normal to flow), and WL (with weld line) specimens.

specimens from the injection molded plates, rectangular strips were cut in a water-cooled diamond saw from the injection molded plates shown in Fig. 1, which were then machined to the dog-bone shape using a high-speed router. The width and gage length of the specimens in the gage area were $12.7 \mathrm{~mm}$ and $40 \mathrm{~mm}$, respectively, and the fillet radius between the gage area and the grip area was $16 \mathrm{~mm}$. A strain gage extensometer $(25 \mathrm{~mm}$ gage length) was used to measure axial strain. The tension tests were conducted at $5 \mathrm{~min}^{-1}$ strain rate and at room temperature. Three parameters were determined from each stressstrain curve: elastic modulus $(E)$ from the initial slope of the stress-strain curve, tensile strength $\left(\sigma_{t}\right)$ corresponding to the maximum stress and failure strain $\left(\varepsilon_{\mathrm{b}}\right)$. Three specimens were tested in uniaxial tension for each injection molding condition. Stress-controlled cyclic fatigue tests were performed in tension-tension mode at the ambient temperature of $\sim 23^{\circ} \mathrm{C}$. The ratio of the minimum cyclic stress to the maximum cyclic stress (i.e., $R$-ratio) was 0.1 . The maximum cyclic stress ranged from $70 \%$ to $90 \%$ of the tensile strength of the material. The cyclic frequency was $1 \mathrm{~Hz}$. Such a low frequency was selected so that fatigue failure would occur instead of thermal failure $[16,18]$. 


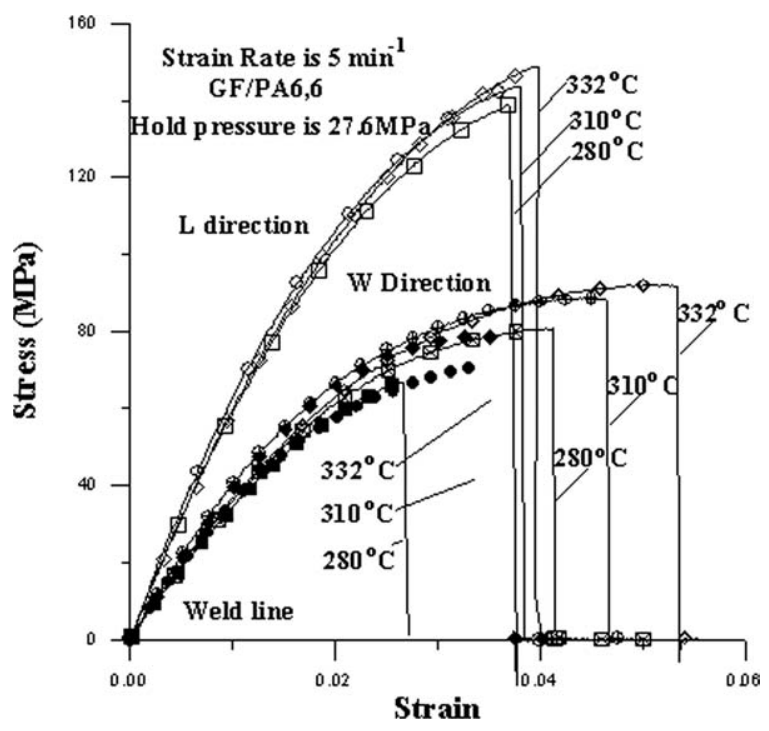

FIG. 2. Effect of melt temperature on tensile stress-strain curves of GF/PA6,6 parallel to the flow direction (L), normal to the flow direction $(\mathrm{W})$, and with the weld line (WL).

\section{RESULTS}

\section{Tensile Properties}

Figures 2 and 3 show the tensile stress-strain curves of the GF/PA-6,6 specimens parallel to the flow direction (L), normal to the flow direction (W), and with weld line (WL) under the different processing conditions considered. The strain rate for these tests was $5 \mathrm{~min}^{-1}$. All specimens failed immediately after the stress reached the maximum value and the failure strain was relatively low. The specimens without the weld line failed in the gage area and the specimens with the weld line failed at the

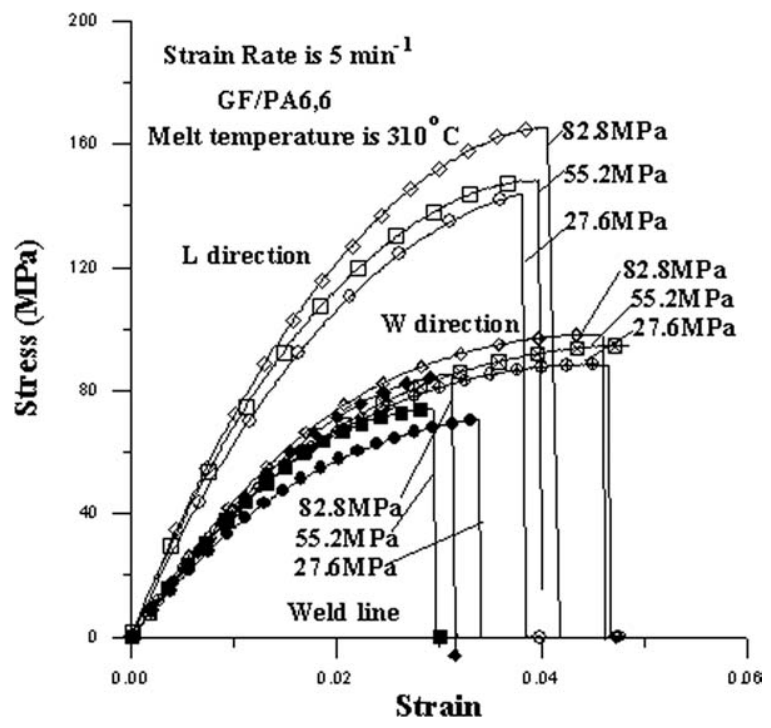

FIG. 3. Effect of hold pressure on tensile stress-strain curves of GF/ PA6,6 parallel to the flow direction (L), normal to the flow direction (W), and with the weld line (WL). weld line, which was located at the mid length of the specimens.

The average tensile properties of the injection molded specimens are given in Table 1 . Both modulus and tensile strength of the material were much higher in the flow direction than normal to the flow direction, but the failure strain in the flow direction was lower. The presence of weld line reduced the modulus, tensile strength, and failure strain even further. The difference in tensile properties in the flow direction and normal to the flow direction is an indication of the inherent anisotropy in the injectionmolded plates, which can be attributed to the preferred orientation of fibers in the flow direction [2, 3]. This will be discussed later in the article.

Figure 2 shows the effect of melt temperature on the tensile behavior of GF/PA-6,6. The hold pressure for these specimens was 27.6 MPa. For specimens parallel to the flow direction as well as normal to the flow direction, tensile strength increased with increasing melt temperature. But the orientation factor for tensile strength, defined as the ratio of tensile strengths of the L-direction and the $\mathrm{W}$-direction specimens, decreased from 1.72 at $280^{\circ} \mathrm{C}$ to 1.57 at $332^{\circ} \mathrm{C}$. On the other hand, the orientation factors for tensile modulus, defined as the ratio of tensile modulus values of the L-direction and the $\mathrm{W}$-direction specimens, were 1.67 at $280^{\circ} \mathrm{C}, 1.78$ at $310^{\circ} \mathrm{C}$, and 1.95 at $332^{\circ} \mathrm{C}$. The orientation factor for tensile modulus can be considered a degree or measure of anisotropy, and thus in this case, anisotropy increased with increasing melt temperature. For specimens with weld line, tensile strength also increased with increasing melt temperature. The weld line factor for tensile strength, defined as the ratio of the tensile strengths of the L-direction specimens and the WL specimens, was 2.07 at melt temperature $280^{\circ} \mathrm{C}$, but it

TABLE 1. Tensile and fatigue properties of GF/PA-6,6 at different processing conditions.

\begin{tabular}{|c|c|c|c|c|c|c|c|}
\hline \multirow[b]{2}{*}{$\begin{array}{c}\text { Melt } \\
\text { temperature } \\
\left({ }^{\circ} \mathrm{C}\right)\end{array}$} & \multirow[b]{2}{*}{$\begin{array}{l}\text { Hold } \\
\text { pressure } \\
(\mathrm{MPa})\end{array}$} & \multirow[b]{2}{*}{ Direction } & \multicolumn{3}{|c|}{ Tensile properties } & \multicolumn{2}{|c|}{$\begin{array}{c}\text { Fatigue } \\
\text { properties }\end{array}$} \\
\hline & & & $\begin{array}{l}\text { Tensile } \\
\text { modulu }\end{array}$ & $\begin{array}{l}\text { Tensile } \\
\text { strength }\end{array}$ & $\begin{array}{l}\text { Failure } \\
\text { strain }\end{array}$ & $\sigma_{c}(\mathrm{MPa})$ & $h$ \\
\hline 280 & 27.6 & $\mathrm{~L}$ & 6.65 & 138.7 & 3.77 & 143.9 & -0.052 \\
\hline 280 & & W & 4.00 & 80.6 & 4.15 & 82.31 & -0.059 \\
\hline 280 & & WL & 3.97 & 66.9 & 2.62 & 63.8 & -0.067 \\
\hline 310 & 27.6 & $\mathrm{~L}$ & 8.35 & 143.6 & 3.79 & 152.0 & -0.059 \\
\hline 310 & & W & 4.69 & 88.5 & 4.89 & 98.6 & -0.063 \\
\hline 310 & & WL & 4.06 & 70.8 & 3.29 & 76.5 & -0.058 \\
\hline 332 & 27.6 & $\mathrm{~L}$ & 9.58 & 148.9 & 0.47 & 160.6 & -0.055 \\
\hline 332 & & W & 4.90 & 94.8 & 5.61 & 100.4 & -0.063 \\
\hline 332 & & WL & 4.37 & 78.9 & 3.51 & 83.8 & -0.064 \\
\hline 310 & 55.2 & $\mathrm{~L}$ & 8.28 & 148.2 & 3.95 & 156.9 & -0.057 \\
\hline 310 & & W & 4.71 & 92.0 & 4.69 & 102.1 & -0.060 \\
\hline 310 & & WL & 4.46 & 74.2 & 3.10 & 82.5 & -0.067 \\
\hline 310 & 82.8 & $\mathrm{~L}$ & 8.65 & 165.5 & 3.99 & 184.6 & -0.060 \\
\hline 310 & & W & 4.95 & 98.3 & 4.77 & 121.0 & -0.067 \\
\hline 310 & & WL & 4.61 & 85.4 & 3.10 & 89.5 & -0.053 \\
\hline
\end{tabular}



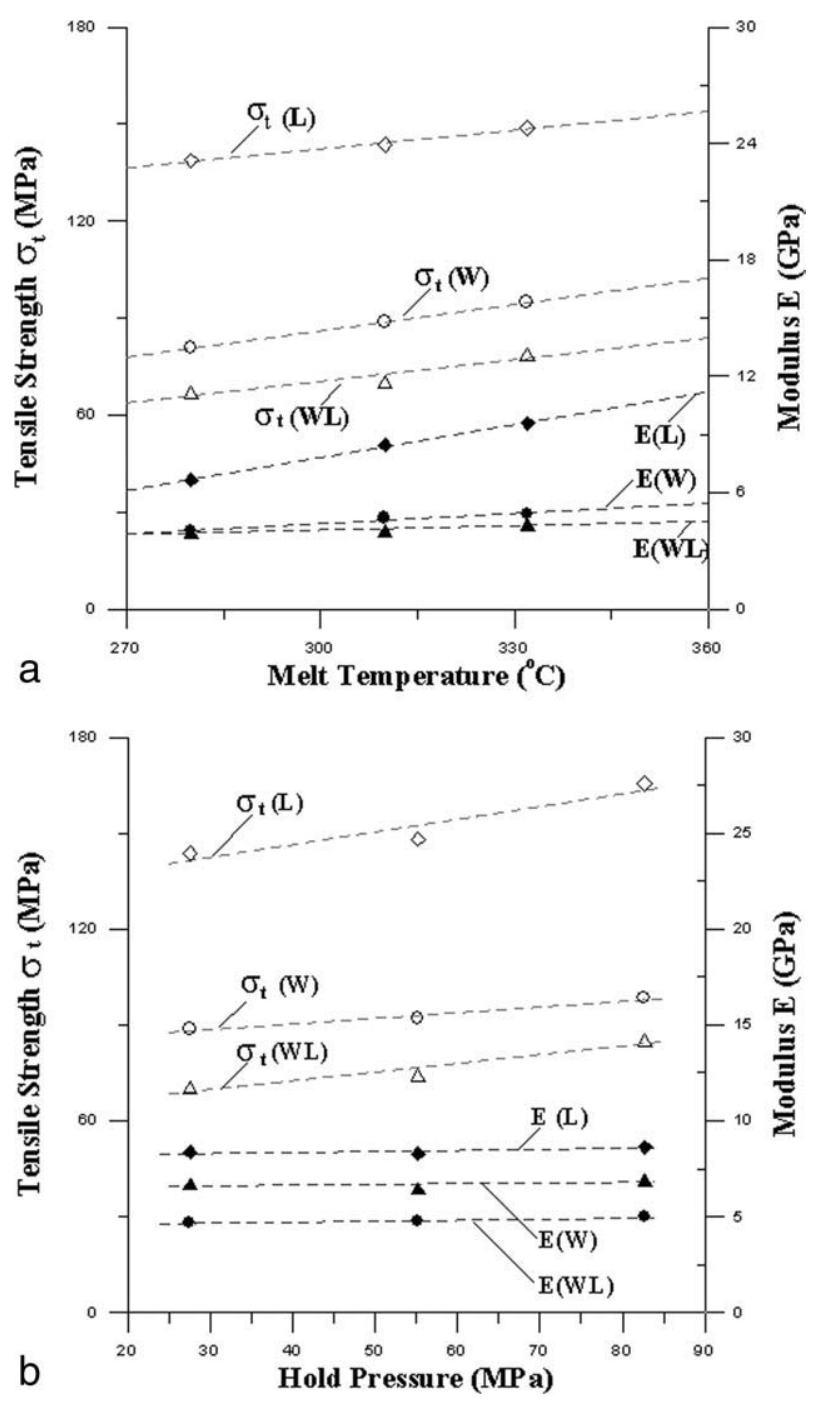

FIG. 4. Effects of (a) melt temperature and (b) hold pressure on tensile strength and modulus of GF/PA6,6 (L: parallel to flow, W: normal to flow, and WL: with weld line).

decreased to 1.89 at melt temperature $332^{\circ} \mathrm{C}$. The weld line factor for tensile strength can be considered a measure of the weakness of the weld line, which in this case, decreased with increasing melt temperature.

Figure 3 shows the effect of hold pressure on the tensile behavior of the GF/PA-6,6. The melt temperature for these specimens was $310^{\circ} \mathrm{C}$. Increasing the hold pressure increased the tensile strength for all three types of specimens. The orientation factors for tensile strength were 1.62, 1.61 , and 1.68 at hold pressures 27.6 $\mathrm{MPa}, 55.2 \mathrm{MPa}$, and $82.8 \mathrm{MPa}$, respectively. Thus the orientation factor for tensile strength was not affected much by hold pressure. The orientation factors for tensile modulus at the three hold pressures were $1.95,1.76$, and 1.75 , respectively. Thus, anisotropy was significantly higher at low hold pressure than at high hold pressure. The weld-line strength increased with increasing hold pressure. The weld line factor for tensile strength decreased from 2.03 at hold pressure $27.6 \mathrm{MPa}$ to 1.997 at hold pressure $82.8 \mathrm{MPa}$. Thus, the measure of weld line weakness was comparatively less sensitive to hold pressure than to melt temperature.

Figures $4 \mathrm{a}$ and $4 \mathrm{~b}$ show that both tensile modulus and tensile strength of the GF/PA-6,6 increased linearly with melt temperature and hold pressure. The linear relationships observed in these plots were modeled using the following equations.

$$
\begin{aligned}
& \sigma_{\mathrm{t}}=\sigma_{\mathrm{to}}\left[\mathbf{1}+J_{\text {melt }}\left(T-T_{0}\right)\right]\left[\mathbf{1}+J_{\text {pressure }}\left(P-P_{0}\right)\right] \\
& E=E_{0}\left[\mathbf{1}+L_{\text {melt }}\left(T-T_{0}\right)\right]\left[\mathbf{1}+L_{\text {pressure }}\left(P-P_{0}\right)\right]
\end{aligned}
$$

where $J_{\text {melt }}, L_{\text {melt }}$ and $J_{\text {pressure }}, L_{\text {pressure }}$ are melt temperature sensitivity factors and hold pressure sensitivity factors, $T_{0}$ and $P_{0}$ are the reference melt temperature and reference hold pressure, and $\sigma_{\text {to }}$ and $E_{0}$ are the reference tensile strength and reference modulus, respectively. The average values of $J_{\text {melt }}, L_{\text {melt }}, J_{\text {pressure, }}$, and $L_{\text {pressure }}$ are listed in Table 2. Equations 1 and 2 can be used to predict the effects of melt temperature and hold pressure on the tensile strength and tensile modulus of this material within the ranges of these parameters considered here.

\section{Fatigue Properties}

Figure 5a shows the S-N curves of the GF/PA-6,6 parallel to the flow direction (L), normal to the flow direction (W), and with weld line (WL) at different melt temperatures. The hold pressure for these specimens was 27.6 $\mathrm{MPa}$. The fatigue strength in the L-direction was much higher than in the $\mathrm{W}$-direction. The presence of weld line decreased the fatigue strength compared to both L-direction and W-direction specimens. Similar to the tensile strength results, melt temperature increased the fatigue strength of GF/PA-6,6 for all three types of specimens.

Figure $5 \mathrm{~b}$ shows the effect of hold pressure on the $\mathrm{S}$ $\mathrm{N}$ curves of the GF/PA-6,6 parallel to the flow direction (L), normal to the flow direction (W), and with weld line (WL). The melt temperature in this case was $310^{\circ} \mathrm{C}$. As before, the L-direction specimens had the highest fatigue strength, and the WL specimens had the lowest fatigue strength. The fatigue strength for all three types of specimens increased with increasing hold pressure. The highest increase occurred when the hold pressure was increased from 27.6 MPa to 82.8 MPa.

TABLE 2. Processing condition factors of GF/PA-6,6.

\begin{tabular}{ccccc}
\hline \multirow{2}{*}{ Property } & Parameter & $\begin{array}{c}\text { In the } \\
\text { flow (L) } \\
\text { direction }\end{array}$ & $\begin{array}{c}\text { Normal to } \\
\text { the flow }(\mathrm{W}) \\
\text { direction }\end{array}$ & $\begin{array}{c}\text { With weld } \\
\text { line }\end{array}$ \\
\hline \multirow{2}{*}{ Yield strength } & $J_{\text {melt }}$ & 0.19 & 0.27 & 0.22 \\
& $J_{\text {pressure }}$ & 0.40 & 0.18 & 0.27 \\
& $J_{\text {melt }}$ & 0.056 & 0.018 & 0.007 \\
Fatigue strength & $J_{\text {pressure }}$ & 0.0050 & 0.0047 & 0.0047 \\
& $K_{\text {melt }}$ & 5.79 & 4.05 & 3.36 \\
& $K_{\text {pressure }}$ & 0.308 & 0.357 & 0.379 \\
& $b$ & -0.05758 & -0.06226 & -0.06168 \\
\hline
\end{tabular}



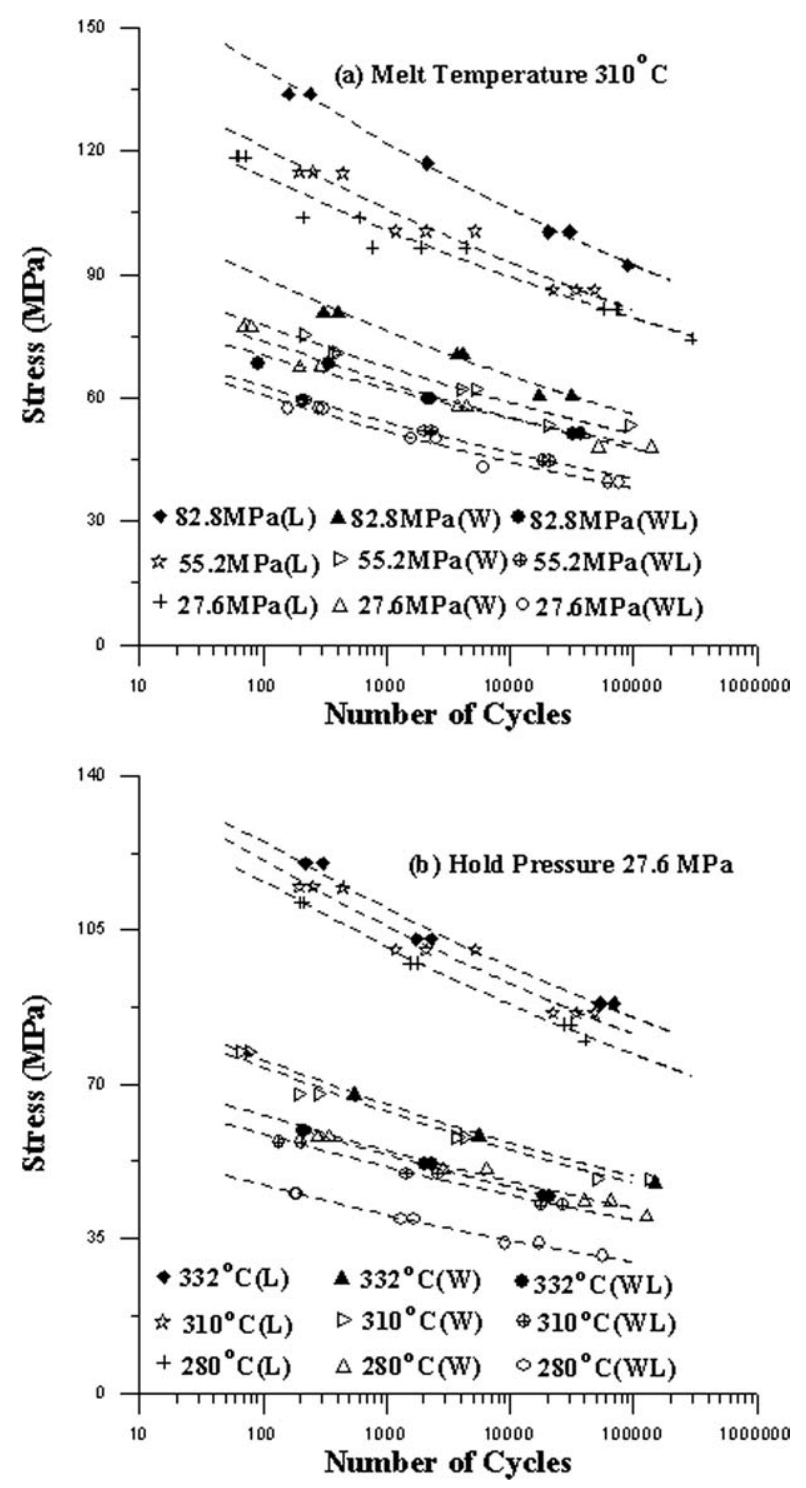

FIG. 5. S-N diagrams of GF/PA6,6 (a) at the same melt temperature, but different hold pressures (b) at the same hold pressure, but different melt temperatures (L: parallel to flow, W: normal to flow, and WL: with weld line).

Based on the experimental results, the following equation was fitted to the $\mathrm{S}-\mathrm{N}$ data corresponding to each processing condition:

$$
\sigma=\sigma_{\mathrm{f}}\left(N_{\mathrm{f}}\right)^{b}
$$

where, $\sigma=$ maximum fatigue stress level, $N_{\mathrm{f}}=$ number of cycles to failure at $\sigma, \sigma_{\mathrm{f}}=$ fatigue strength coefficient, and $b=$ fatigue strength exponent. Equation 3 is called the Basquin equation and is used to model the stress-life data of metals [23]. The values of fatigue strength coefficient $\sigma_{\mathrm{f}}$ and fatigue strength exponent $b$ at different processing conditions are listed in Table 1 and are plotted in Figs. 6 and 7 as a function of hold pressure and melt temperature, respectively.

Figure 6 shows the variation of fatigue strength coefficient $\sigma_{\mathrm{f}}$ and fatigue strength exponent $b$ with hold pressure. The values of $\sigma_{\mathrm{f}}$ for all three types of specimens increased with increasing hold pressure; however, the fatigue strength exponent $b$ was not much affected by hold pressure. Thus, in the range of hold pressures considered, $b$ was assumed to be a constant. Figure 7 shows that the fatigue strength coefficient, $\sigma_{\mathrm{f}}$, for the L-direction specimens, W-direction specimens and WL specimens also increased with increasing melt temperature. Figure 7 also shows that the variation of fatigue strength exponent $b$ with melt temperature was very small, and therefore, in the melt temperature range considered, $b$ was assumed to be a constant. The following relationship was found to fit the combined effect of melt temperature and hold pressure on $\sigma_{\mathrm{f}}$.

$$
\sigma_{\mathrm{f}}=\sigma_{\mathrm{fo}}\left[\mathbf{1}+K_{\text {melt }}\left(T-T_{0}\right)\right]\left[\mathbf{1}+K_{\text {pressure }}\left(P-P_{0}\right)\right]
$$

where $K_{\text {melt }}$ and $K_{\text {pressure }}$ are melt temperature sensitivity factor and hold pressure sensitivity factor in fatigue, $T_{0}$ and $P_{0}$ are reference melt temperature and reference hold pressure, and $\sigma_{\text {fo }}$ is the reference fatigue strength coefficient. The average values of $K_{\text {melt }}, K_{\text {pressure }}$, and $b$ of the GF/PA-6,6 are listed in Table 2.

\section{Fracture Surface Observations}

The fracture surfaces of several fatigue specimens were examined under scanning electron microscope to determine the differences in the L-direction, W-direction, and WL specimens. The significant difference in tensile and fatigue properties in the L- and $\mathrm{W}$-directions indicates inherent anisotropy of the injection-molded plates, which can be attributed to the preferred orientation of fibers in the flow direction. Preferred orientation of short fibers in the flow direction of injection molded specimens has been observed by several investigators [1-5]. In general, the greater the fiber orientation parallel to the loading direction, the higher will be the modulus and strength, since

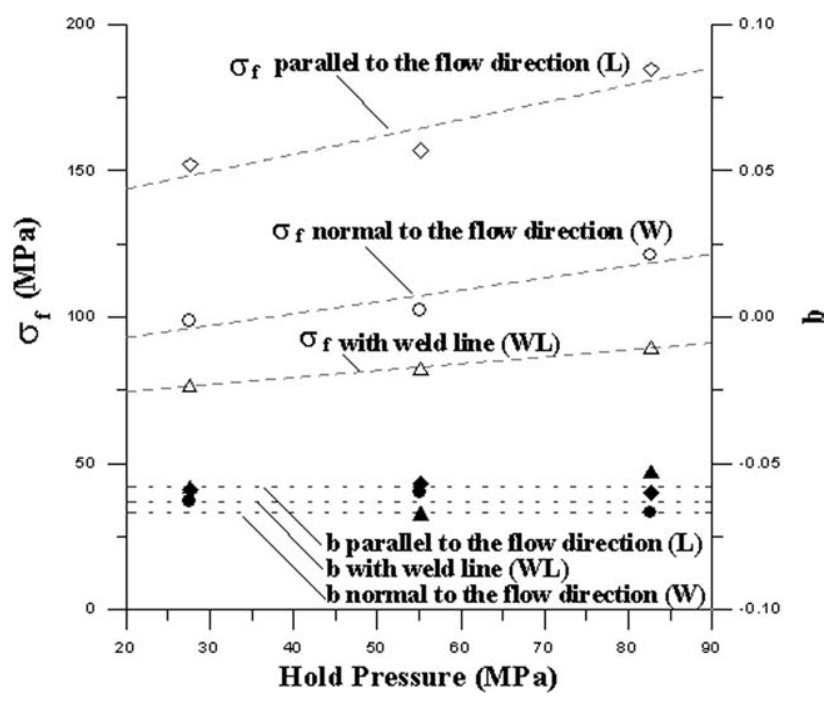

FIG. 6. Effect of hold pressure on the fatigue strength coefficient $\sigma_{\mathrm{f}}$ and fatigue strength exponent $b$ at melt temperature $310^{\circ} \mathrm{C}$ (L: parallel to flow, W: normal to flow, and WL: with weld line). 


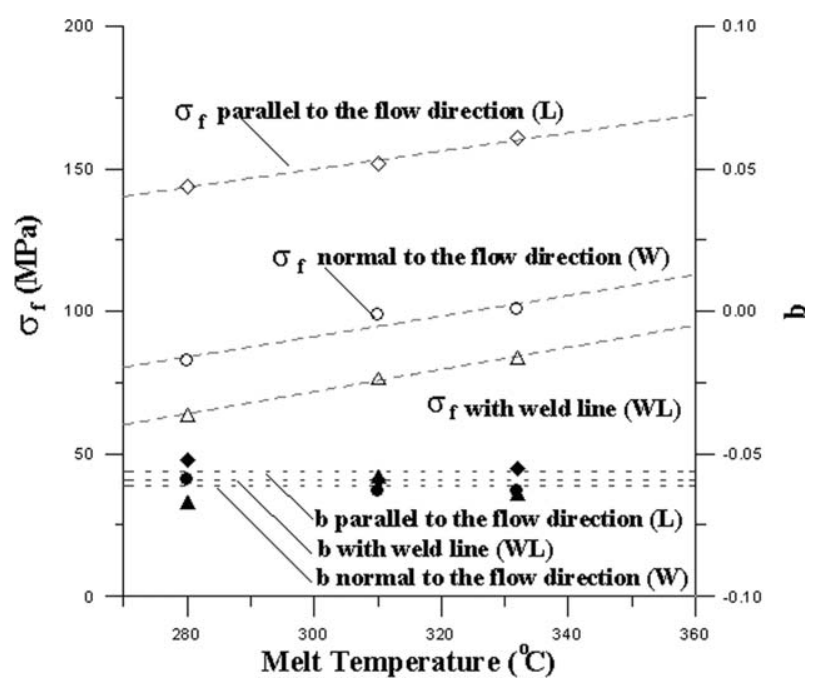

FIG. 7. Effect of melt temperature on the fatigue strength coefficient $\sigma_{\mathrm{f}}$ and fatigue strength exponent $b$ at hold pressure 27.6 MPa (L: parallel to flow, W: normal to flow, and WL: with weld line).

fibers parallel to the loading direction are more effective in stress transfer from the matrix to the fibers than those oriented normal to the loading direction.
Figures 8-10 show the fracture surfaces of GF/PA-6,6 in the flow direction, with weld line and normal to the flow direction, respectively. For the specimen in the flow direction, i.e., the L-direction specimen, short glass fibers were mostly parallel to the flow direction, which was also the loading direction in both tensile and fatigue tests. For the specimen with the weld line, i.e., the WL specimen, fibers in the failure zone (i.e., at the weld line) were mostly parallel to the fracture surface, i.e., normal to the loading direction. For the specimen normal to the flow direction, i.e., the $\mathrm{W}$-direction specimen, a skin-core morphology was clearly visible. The core contained a band of short fibers oriented mostly normal to the fracture surface and the skin contained a band of short fibers mostly parallel to the fracture surface. Gupta and Wang [24] noted similar fiber orientation difference in the flow direction and normal to the flow direction in a single-gated rectangular cavity. Results from their simulations show that near the surfaces where the polymer tends to solidify quickly, the shear-dominated flow tends to align the fibers parallel to the flow direction throughout the entire cavity. Toward the mid-thickness of the cavity, the flow front takes the shape of approximately
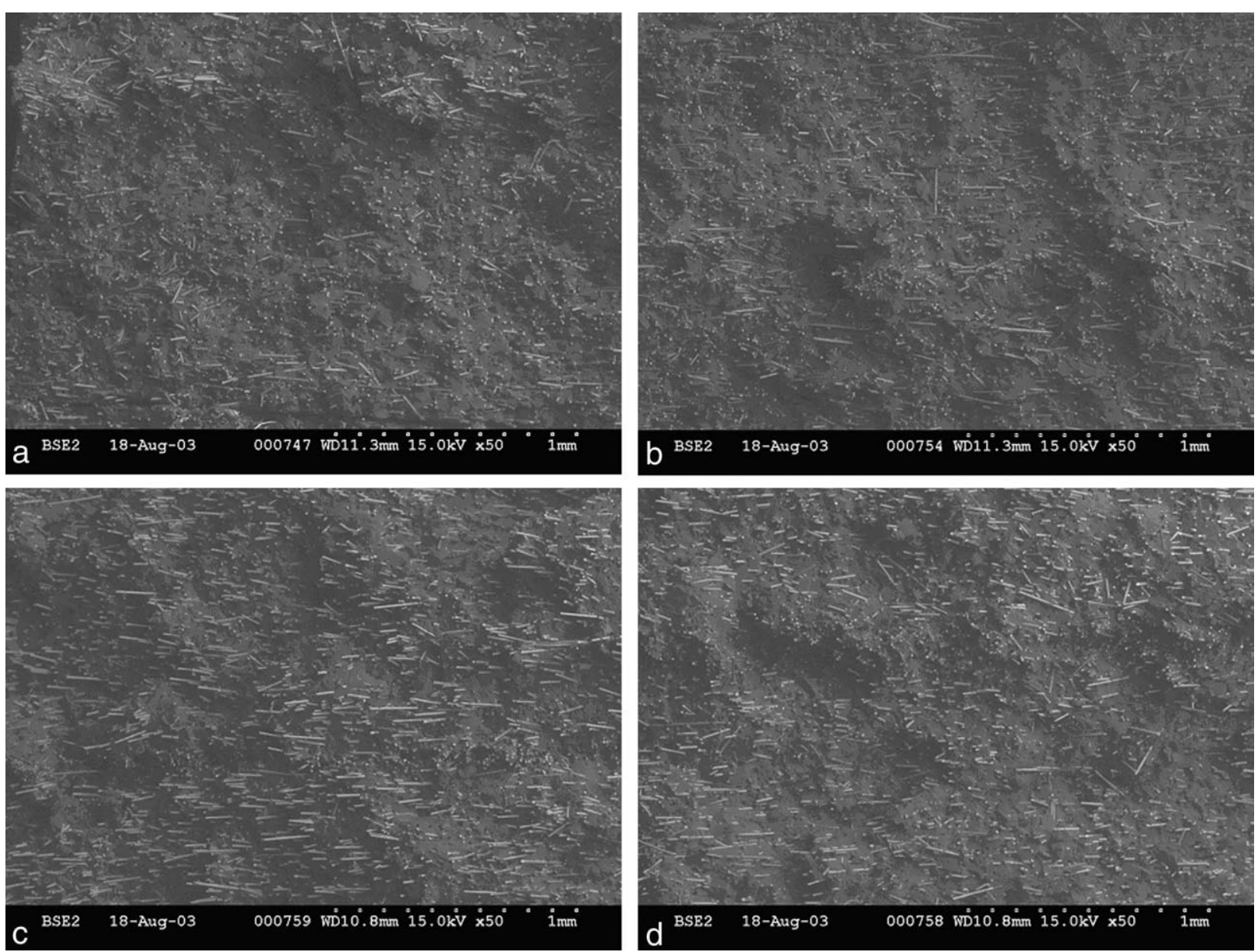

FIG. 8. SEM micrographs of fatigue fracture surfaces of specimens parallel to the flow direction (i.e., L-direction specimens); (Hold pressure and melt temperature are (a) $27.6 \mathrm{MPa}, 310^{\circ} \mathrm{C}$, (b) $82.8 \mathrm{MPa}, 310^{\circ} \mathrm{C}$, (c) $27.6 \mathrm{MPa}, 280^{\circ} \mathrm{C}$ and (d) $27.6 \mathrm{MPa}, 332^{\circ} \mathrm{C}$ ). 

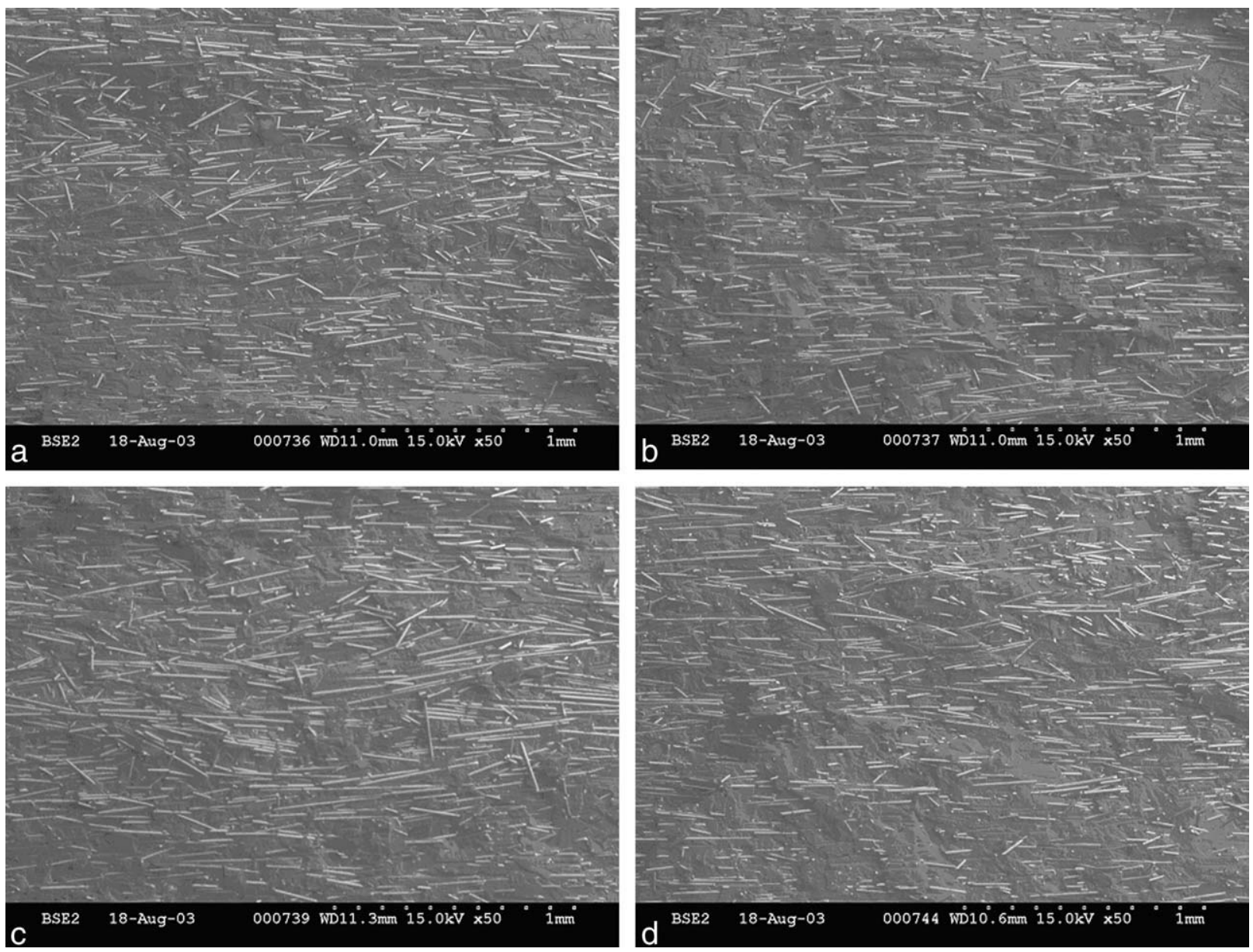

FIG. 9. SEM micrographs of fatigue fracture surfaces of specimens containing weld line (i.e., WL specimens); (Hold pressure and melt temperature are (a) $27.6 \mathrm{MPa}, 332^{\circ} \mathrm{C}$, (b) $82.8 \mathrm{MPa}, 310^{\circ} \mathrm{C}$, (c) $55.2 \mathrm{MPa}$, $310^{\circ} \mathrm{C}$ and (d) $27.6 \mathrm{MPa}, 280^{\circ} \mathrm{C}$ ).

concentric circles of increasingly larger diameter as it diverges out toward the end of the cavity. The fibers at the mid-thickness are parallel to the flow front, which means they are aligned $90^{\circ}$ to the flow direction near the centerline of the cavity, but are oriented at angles less than $90^{\circ}$ toward the two edges of the cavity. This creates the skin-core morphology of the type seen in Fig. 10 for normal to the flow direction specimens that were located near the gate. However, for the L-direction specimens taken in the flow direction from the two sides of the molded plates, the fiber orientation remains mostly parallel or nearly parallel to the flow direction, even near the mid-thickness, which explains the lack of clear skin-core morphology in these specimens. Kim et al. [25] studied the through-thickness fiber orientation in weld lines formed behind a rectangular insert in which the divided flow fronts joined together to form the type II weld line much like the one seen in this study. Their simulation results show that the fiber orientation at the weld line is parallel to the weld line at or close to the mid-thickness. Even toward the surfaces, fiber orientation is very close to being parallel to the weld line except at locations just behind the insert.
Both modulus and strength of a short fiber reinforced composite are controlled by fiber orientation [26]. In this study, these two tensile properties were the highest for the L-direction specimens and the lowest for the WL specimens due to near-parallel and near-transverse fiber orientations, respectively, with respect to the loading direction. The intermediate tensile properties of the Wdirection specimens were due to the skin-core morphology in which fibers in the skins were oriented normal to the loading direction, whereas fibers in the core were oriented parallel to the loading direction. Strength normal to the flow direction was lower than that in the flow direction, but the failure strain normal to the flow direction was higher than that in the flow direction. For specimens in the flow direction and with the weld line, the fracture surfaces at different processing conditions were similar. But for specimens normal to the flow direction, the thickness of the core containing fibers parallel to the loading direction was influenced by the two processing conditions considered. For example, at $310^{\circ} \mathrm{C}$ melt temperature, the core thicknesses were $\sim 0.32 \mathrm{~mm}, 0.41 \mathrm{~mm}$, and $0.83 \mathrm{~mm}$ at hold pressures $27.6 \mathrm{MPa}, 55.2 \mathrm{MPa}$, and $82.8 \mathrm{MPa}$, respectively. Similarly, at $27.6 \mathrm{MPa}$ hold pressure, the 

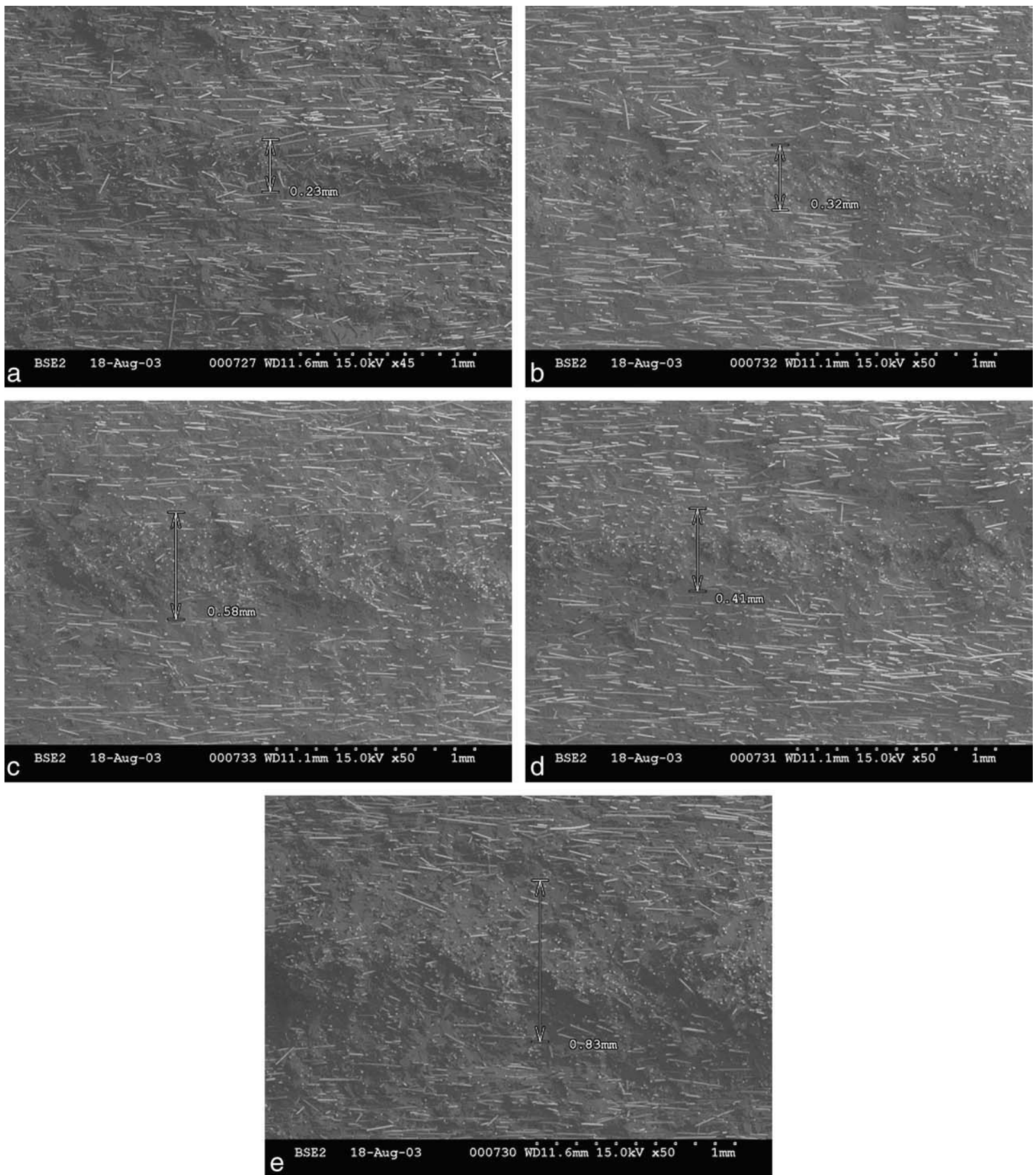

FIG. 10. SEM micrographs of fatigue fracture surfaces of specimens normal to the flow direction (i.e., W-direction specimens); (Hold pressure and melt temperature are (a) $27.6 \mathrm{MPa}, 280^{\circ} \mathrm{C}$, (b) $27.6 \mathrm{MPa}$, $310^{\circ} \mathrm{C}$, (c) $27.6 \mathrm{MPa}, 332^{\circ} \mathrm{C}$, (d) $55.2 \mathrm{MPa}, 310^{\circ} \mathrm{C}$, and (e) $82.8 \mathrm{MPa}, 310^{\circ} \mathrm{C}$ ).

core thicknesses were $\sim 0.23 \mathrm{~mm}, 0.32 \mathrm{~mm}$, and $0.58 \mathrm{~mm}$ at melt temperatures $280^{\circ} \mathrm{C}, 310^{\circ} \mathrm{C}$, and $332^{\circ} \mathrm{C}$, respectively. In both cases, both tensile modulus and strength showed increasing trend with increasing core thickness, since in these specimens, the fibers in the core were mostly oriented in the tensile stress direction.

No attempt has been made in this article to analytically relate the tensile properties to core-shell fiber dis- tributions. Skourlis et al. [27] have shown that an injection molded plate can be modeled as a three layer (shell-core-shell) composite structure in which each layer is characterized by an average orientation of fibers and average fiber length. The layer characteristics are determined by conducting experiments that were beyond the scope of this article. Modeling for strength is significantly more difficult, since it requires the knowledge 
of the fiber-matrix interface characteristics and location and intensity of molding defects (e.g., residual stresses) as well.

\section{CONCLUSIONS}

Static tensile and fatigue tests have been performed on GF/PA-6,6 injection molded at three different melt temperatures and three different hold pressures. Tensile strength and fatigue strength of the GF/PA-6,6 specimens were lower normal to the flow direction than in the flow direction, indicating inherent anisotropy in the material. Tensile strength and fatigue strength of the GF/PA-6,6 with weld line were significantly lower than those without weld line. Tensile strength and fatigue strength for all three types of specimens increased with increasing melt temperature as well as increasing hold pressure.

\section{REFERENCES}

1. G. Pötsch and W. Michaeli, Injection Molding, Hanser Publishers, Munich, Germany (1995).

2. J. Bowman, N. Harris, and M. Bevis, J. Mater. Sci., 10, 63 (1975).

3. M.W. Darlington, P.L. McGinley, and G.R. Smith, J. Mater. Sci., 11, 877 (1976).

4. M.W. Darlington, B.K. Gladwell, and G.R. Smith, Polymer, 18, 1269 (1977).

5. M. Fujiyama, H. Awaya, and S. Kimura, J. Appl. Polym. Sci., 21, 3291 (1977).

6. M. Akay and D. Barkley, J. Mater. Sci., 26, 2731 (1991).

7. P. Dave and D. Chundury, J. Inj. Mold. Tech., 1, 181 (1997).

8. S.E. Barbosa and J.M. Kenny, J. Reinf. Plast. Compos., 18, 413 (1999).
9. N. Sanjeeva Murthy, V.A. Kagan, and R.G. Bray, Polym. Eng. Sci., 42, 940 (2002).

10. A. Arzak, J.I. Eguiazábal, and J. Nazábal, Plast. Rubber Compos. Process Appl., 17, 165 (1992).

11. E.W. Liang and V.K. Stokes, Polym. Compos., 26, 428 (2005).

12. Y. Zhou and P.K. Mallick, Polym. Eng. Sci., 45, 755 (2005).

13. J.L. Thomason, Compos. Sci. Technol., 59, 2315 (1999).

14. M. Akay, D.F. O'Regan, and R.S. Bailey, Compos. Sci. Technol., 55, 109 (1995).

15. M. Akay and D.F. O'Regan, Polym. Test, 14, 149 (1995).

16. I. Lévay, G.B. Lenkey, L. Tóth, and Z. Major, J. Mater. Process. Technol., 133, 143 (2003).

17. N. Jia and V.A. Kagan, Polym. Compos., 19, 4 (1998).

18. Y. Zhou and P.K. Mallick, Polym. Compos., 27, 230 (2006).

19. A. Bernasconi, P. Davoli, A. Basile, and A. Filippi, Int. J. Fatigue, 29, 199 (2007).

20. A.T. DiBenedetto and G. Salee, Polym. Eng. Sci., 19, 513 (1979).

21. J. Karger-Kocsis and K. Friedrich, Composites, 19, 105 (1988).

22. M.G. Wyzgoski and G.E. Novak, J. Mater. Sci., 26, 6314 (1991).

23. J.A. Bannantine, J.J. Comer, and J.L Handrock, Fundamentals of Metal Fatigue Analysis, Prentice Hall, Englewood Cliffs, NJ, USA (1990).

24. M. Gupta and K.K. Wang, Polym. Compos., 14, 367 (1993).

25. J.K. Kim, J.H. Song, S.T. Chung, and T.H. Kwon, Polym. Eng. Sci., 37, 228 (1997).

26. F.L. Matthews and R.D. Rawlings, Composite Materials: Engineering and Science, Chapman and Hall, London (1994).

27. T.P. Skourlis, K. Pochiraju, C. Chassapis, and S. Manoochehri, Composites B, 29B, 309 (1998). 